\title{
Effects of an Indigenous Food Diet on Nutritional Outcomes for Under-Five Children in Early Childhood Development Centres, Limpopo Province, South Africa: A Pretest-Posttest Quasi-Experimental Study
}

Gundo Nepfumbada ( $\square$ gmalis30@gmail.com )

University of KwaZulu-Natal College of Health Sciences https://orcid.org/0000-0002-1476-2482

Boikhutso Tlou

University of KwaZulu-Natal College of Health Sciences

Tivani Phosa Mashamba-Thompson

University of KwaZulu-Natal College of Health Sciences

Research article

Keywords: Indigenous food diet, Early childhood development, under-five children

Posted Date: February 15th, 2021

DOI: https://doi.org/10.21203/rs.3.rs-234368/v1

License: (1) (i) This work is licensed under a Creative Commons Attribution 4.0 International License.

Read Full License 


\section{Abstract}

Background: Access to an adequate diet is a key criterion for improving nutritional status. Indigenous food (IF) can play a big role in improving dietary variety in rural populations. The aim of the study was to assess the effectiveness of an IF diet for under-five children in Early childhood development (ECD) centres.

Method: A one-group pretest-posttest experimental design study was undertaken in three ECD centres from three different villages of Sekhukhune district, the former Fetakgomo municipality, in Limpopo, South Africa. An IF diet intervention was implemented for a period of six months with 253 children aged 0-5 attending three ECD centres. Anthropometric measurements were taken pre-introduction of an IF diet and post-intervention. The dependent sample t-Test was used to compare the pre- and postanthropometric measures, and a $p$-value $<0.5$ was deemed statistically significant.

Results: Significant improvement in the nutritional outcomes of the participating children were recorded, a majority $(50 \%)$ of who were aged three. The study showed significant differences in pre- and postanthropometric measurements for weight $\mathrm{p}<0.0001$ and Mid-Upper Arm Circumference (MUAC) $(p=0.002)$, whilst there was not any significant difference on pre- and post-height measurements $(p=0.857)$.

Conclusion: The adapted IF diet is shown to be effective for the nutritional outcomes of children and can be used to promote the use of IF and address nutritional deficiencies amongst under-five children in Limpopo, South Africa.

\section{Background}

Due to its health benefits, Indigenous food (IF) plays an important role in people's diets. Adequate intake of fruit and vegetables has been related to a reduced risk of many non-communicable diseases worldwide (1). Several studies conducted in Sub-Saharan Africa on the benefits of their intake has on nutrition reported that IF is a major source of nutrients, essential for proper growth and development of children and useful in treating micronutrient deficiencies (1-4). A 2014 quasi-experimental study conducted by Masuda in Zambia on the effectiveness of spirulina in child malnutrition revealed the effectiveness of its consumption on improving nutritional status, linear growth and addressing severe stunting in children (5). However, under nutrition persists, especially in rural Sub-Saharan Africa where one in three children are chronically malnourished and micronutrient deficiencies prevail (6). According to a 2018 Global Nutrition report, about a third $(30,3 \%)$ of school-aged children do not eat any fruit daily (7). The same report revealed that in Africa $40 \%$ of children are stunted, $27 \%$ are wasted and $24 \%$ are overweight (8). The 2019 United Nations Children's Fund (UNICEF) report revealed that one in three underfive children are not growing well. This is despite the national development plan (NDP 2030) target to eradicate micronutrient deficiencies through nutrition interventions for children (NDP 2030). Provision of adequate, diverse and nutritious food at an early age is crucial for malnutrition prevention (9). 
South Africa experiences a malnutrition burden among its under-five population, showing that micronutrient deficiency is still rife despite concentrated efforts to curb it (10). Coinciding with the burden of under nutrition is the increasing prevalence of overweight and obesity as well as diet-related noncommunicable diseases (11). Some studies show that the diet given to children in most South African rural areas lacks variety and falls short of recommended quantities of fruit and vegetables and other protein-rich food, resulting in poor nutrition $(6,12)$. It is important to note that a decline in the dietary use of IF and its replacement with westernized fatty foods has been linked to the increase in micronutrient deficiencies (13). The South African Food Based Dietary Guidelines (FBDG) report that in South Africa diets given to children are energy dense from highly processed, micronutrient-poor convenience foods and contribute to mordility and mortality (10).

Poor feeding practices with insufficient quantity and inadequate quality of nutritious food is a threat to the health and nutrition of children (14). This is contrary to the FBDG recommendation of daily consumption of a variety of fruit and vegetables among children (10). Verstraeten et al. (2014) also reported that taste and preparation methods of IF have an important impact on preference and consumption of IF among children (15). Indigenous knowledge is fast eroding and the skills of preparation, preservation, processing and storage of IF are diminishing (16). Given this loss of knowledge, preference for ready-to-eat-food has grown and is a significant barrier to healthy eating (15).

Food insecurity continues to put children in a vulnerable state of poor nutritional outcomes due to inadequate diets (17). Improving food security and improving nutrition is at the heart of the Sustainable Development Goals (SGDs) Food and Agriculture Organization (FAO, 2016B); SDG 2 seeks to end hunger, achieve food security, improve nutrition and promote sustainable agriculture; SDG 3 aims to ensure healthy lives and promote well-being for all ages (18). It is a challenge to achieve SDG 2 and 3 without addressing nutrition (Global report 2019). The UNICEF child and nutrition report, 2019, showed that poverty is at the heart of malnutrition; diets of poor people are missing whole grains, fruit and vegetables and omega-3 fatty acids. In 1995, the FBDG became part of the FAO/World Health Organisation (WHO) strategy to promote appropriate diets through recommendations of optimal dietary patterns and healthy lifestyles (10). Though the FBDG recommendations were made, little is known of their successes and failures (10). Furthermore, the analysis of sustainable diets and food systems has predominantly focused on high-income countries and overlooked the relevance of resource-limited settings (11). Given this background, our study seeks to assess the effects of an IF diet on nutritional outcomes for under-five children in rural ECD centres. Implementation of this diet will promote and scale up the frequent use of IF in rural ECD centres. This dietary menu will ease financial burdens for food for both ECD centres and the Department of Social Development, responsible as funders, as IF is less expensive and accessible.

\section{Methods}

\section{Study design and population}


This study employed a group pre- and post-experimental design to address the research objective. Anthropomentric measurements (height, weight and MUAC) were collected at baseline for children aged under five and an IF diet intervention was implemented for a period of six months, and post-intervention measurements were then taken for the children. The study population included children aged under five in three ECD centres in the former Fetakgomo municipality. According to the Statistics South Africa community survey in 2016, Sekhukhune district had a population of approximately 1169 762, with Fetakgomo municipality at 96668 people, and children below the age of five accounting for over $11,03 \%$. Fetakgomo-Tubatse is one of the four municipalities in the Sekhukhune district and is the biggest, accounting for $42 \%$ of the geographic area with villages scattered throughout, containing over 2200 indigenous plant and animal species. There are approximately 95 funded ECD centres in the former Fetakgomo municipality.

The study was conducted in Fetakgomo-Tubatse municipality, Sekhukhune district, which is located north of the N4 highway to Middleburg and east of the N4 highway to Polokwane, Limpopo province in South Africa. It covers 4550 square kilometers in size. Sekhukhune is one of the five districts in Limpopo with $53 \%$ of severely food insecure households (1). Agriculture is the most important source of income followed by social grants, with most families classified as poor or indigent (2). A majority of commercial farmers depend on irrigation systems for farming due to shortages of water and poor rainfall distribution (3).

Simple random sampling was used to select three ECD centres from Fetakgomo-Tubatse municipality. All children from the three ECD centres whose parents gave consent to participate and met the inclusion criteria were included in the study. A total of 253 children were included at baseline, and post-intervention, 250 children were available for post-test measurements, with three children lost to follow-up due to school migration.

\section{Data collection}

Parents of children accessing the three selected ECD centres gave written consent for their participation in the study. Visits were conducted to ECD centres for measurements to be taken on each child, done by the researcher, researcher assistant and a dietician. Anthropometric measurements were taken at baseline and post the intervention on every child. The researcher assistance conducted visits twice a month to the ECD centres to ensure compliance with the IF diet, which was provided to the ECD centres on a monthly basis by the researcher, with some food items procured through funding by the Department of Social Development.

\section{Nutritional status}

The four study anthropometric parameters (height, weight and MUAC) of under-five children were measured using the WHO recommended standard measuring equipment. This study used three indicators to assess the nutritional status of under-five children pre- and post-intervention: height-for-age $z$-score (HAZ), weight-for-age z-score (WAZ), weight-for-height (WHZ) and mid-upper arm circumference (MUACZ). The HAZ is an indicator of chronic malnutrition, while the WAZ and MUACZ are indicators of 
chronic, current malnutrition and malnutrition respectively. The WHO and UNICEF define stunting as children whose height-for-age $z$-score is below minus two standard deviations ( $\mathrm{HAZ}<-2)$ and underweight as those children whose weight-for-age $z$-score is below minus two standard deviations (WAZ<-2). If these indicators are minus three (-3) standard deviations and below, the child's nutritional status is considered severe. Anthropo software, designed by the WHO, was utilized to calculate growth indicators using the height, weight and MUAC data.

\section{Indigenous food diet}

The IF diet was co-created through a focus group discussion by ECD stakeholders and experts in children's diet; the manuscript on the co-creation of the IF diet is under consideration for publication elsewhere. The menu comprised eleven varieties of IF, fruit, vegetables and mixed dishes. The study followed the 2016 nutrition guidelines for ECD, with a recommended menu for breakfast, lunch and a snack. It was also based on the South African FBDG, paediatric FBDG and the WHO growth standard for children $(10,20)$. The diet was designed as the recommended weekly plan menu. The FBDG addresses both dietary adequacy and prudency, and encourages plenty of and daily consumption of fruit and vegetables to promote overall health and chronic disease prevention (10).

\section{Implementation of the IF diet}

The IF diet was presented to the parents and caregivers of the children after they signed their consent for their participation in the intervention prior the implementation. The diet was welcomed by parents, who suggested they also use the same diet at home and during the school holidays. The IF diet was implemented for the period of six months and was designed to be used on the school days from Monday to Friday. The consumption frequency of different food groups was categorized as daily, twice, and three times a week. The diet considered the availability, accessibility, acceptability and suitability of IF to the children. Types of IF included on the menu were mixed dishes, fruit and vegetables, and the full menu is presented in Appendix A.

\section{Data analysis}

Data were collected and analysed using SPSS (statistical package for social sciences) version 27 and a p-value less than 0.05 was deemed as statistically significant. Frequency distribution tables and proportions were used to summarize the demographic characteristics of the study participants. The dependent samples-t-test was used to assess the significance of the baseline and post-intervention differences of the children's nutritional indicators. If there was no difference between the two periods, it implied that the child growth was according to the children's growth curve.

\section{Results}

\section{Socio-demographic data}


The participants ages ranged from age one to five and the majority of the participants were aged three $(24.8 \%)$ and four (50\%). The study showed that $52 \%(133)$ were males and $48 \%(120)$ were females. The majority of children, at $95,6 \%$, depended on social grants as the family means of survival. The study further showed that only $7,1 \%$ of the parents had tertiary education, with $73,9 \%$ of them with primary to secondary education. Anthropometric measurements were taken from all children participating in the study. The demographic characteristics of the participating children are presented in the Table 1 below.

\begin{tabular}{|c|c|c|c|}
\hline \multicolumn{4}{|c|}{ Table 1: Demographic characteristics of the study participants } \\
\hline & Category & Frequency & $\%$ Total \\
\hline Gender & Male & 133 & 52 \\
\hline & Female & 120 & 48 \\
\hline Age (years) & 1 & 3 & 1.2 \\
\hline & 2 & 20 & 8 \\
\hline & 3 & 62 & 24.8 \\
\hline & 4 & 127 & 50 \\
\hline & 5 & 38 & 15.2 \\
\hline Family income & Social grant & 242 & 95.6 \\
\hline & salary & 8 & 3.2 \\
\hline Parents education & No formal education & 48 & 18.9 \\
\hline & Primary to secondary & 187 & 73.9 \\
\hline & Tertiary education & 18 & 7.1 \\
\hline
\end{tabular}

Anthropometric measures were taken according to the standard methods recommended by the WHO. Three pairs were used in the study, where first pair entailed the weight, second pair entailed height and the third pair was made of MUAC. The mean and standard deviation of the pre-weight were 15.068 and 2.3234 respectively while the mean and standard for post-weight was 15.427 and 2.3646 respectively. In terms of height, the pre-height mean and standard deviation were 0.96956 and 0.124 correspondingly while for post-height were 1.1796 and 2.24. Concerning MUAC, the pre mean and standard deviation were 13.97 and 1.908 whereas the post were 15.35 and 7.882 respectively. Table 2 below summarizes the descriptive statistics for the experiment results. 
Table 2

Comparison between pre- and post-results for growth indicators

\begin{tabular}{|c|c|c|c|c|c|}
\hline & & Mean & $\mathbf{N}$ & Std. Deviation & p-value \\
\hline \multirow[t]{2}{*}{ Pair 1} & Pre-weight & 15.068 & 250 & 2.3234 & \multirow[t]{2}{*}{$p<0.0001$} \\
\hline & Post-weight & 15.427 & 250 & 2.3646 & \\
\hline \multirow[t]{2}{*}{ Pair 2} & Pre-height & 0.96956 & 250 & .124190 & \multirow[t]{2}{*}{$p=0.857$} \\
\hline & Post-height & 1.17964 & 250 & 2.240025 & \\
\hline \multirow[t]{2}{*}{ Pair 3} & Pre-Muac & 13.97 & 250 & 1.908 & \multirow[t]{2}{*}{$p=0.002$} \\
\hline & Post-Muac & 15.35 & 250 & 7.882 & \\
\hline
\end{tabular}

The results showed that there was a statistically significant difference between the pre- and post-mean weights $(p<0.0001)$ and MUACs $(p=0.002)$, whereas height $(p=0.857)$ showed no significant difference. The difference between the mean pre- and post-intervention weights showed an increase in weight from baseline. In addition to that, there was an increase in the mean height from baseline measurements, even though it was not statistically significant. There was also an increase between the mean pre-and postintervention MUAC measurements.

\section{Descriptive analysis pre- and post-intervention}

The average improvement in the children's nutritional indicators and the difference between June 2019 (baseline) and November 2019 (endline) are summarised in Table 3 below. Each index is standardised into a z-score value. The change on children's growth post the intervention was higher as compared to pre intervention assessment in all indicators. For example, the difference in weight were recorded, the rate of children with normal WAZ was $98 \%$ post intervention. HAZ was at $99.2 \%$ post the intervention, in MUAC, the rate of children at risk of acute malnutrition decreased by $17.6 \%$ post the intervention.

\section{Anthropometric status}




\begin{tabular}{|c|c|c|c|}
\hline Z-score classification & Interpretation & $\begin{array}{l}\text { Baseline } \\
n=250 \\
n(\%)\end{array}$ & $\begin{array}{l}\text { End line } \\
n=250 \\
n(\%)\end{array}$ \\
\hline HAZ WHO classification & Severely stunted (<-3SD) & 4 & 8 \\
\hline$<-3 S D$ & Stunted (-3SD-<-2SD) & 0 & 0 \\
\hline$-3 S D-<-2 S D$ & Mildly stunted (-2SD $-<-1 S D)$ & 0 & 0 \\
\hline \multicolumn{4}{|l|}{$-2 S D-<-1 S D$} \\
\hline & Normal height (-1SD-+1SD) & 0 & 0 \\
\hline & $\begin{array}{l}\text { Normal height (>+1SD- } \\
\leq+2 S D)\end{array}$ & 96.8 & 99.2 \\
\hline \multicolumn{3}{|l|}{$<-3 S D$} & 0 \\
\hline$-3 S D-<-2 S D$ & Underweight & 0 & 0 \\
\hline$-2 S D-<-1 S D$ & Mildly underweight & 0 & 0 \\
\hline -1SD-+1SD & Normal WAZ & 98.0 & 98.0 \\
\hline$>+1 S D-\leq+2 S D$ & Possible growth problem & 2 & 2 \\
\hline$>+2 S D-\leq+3 S D$ & Possible growth problem & 0 & 0 \\
\hline WHZ WHO classification & Severely wasted & 0 & 0 \\
\hline$<-3 S D$ & Wasted & 0 & 0 \\
\hline$-3 S D-<-2 S D$ & Mildly wasted & 2.0 & 4 \\
\hline \multicolumn{4}{|l|}{$-2 S D-<-1 S D$} \\
\hline \multirow[t]{3}{*}{ WAZ } & Normal WAZ (-1SD-+1SD) & 95.6 & 99.6 \\
\hline & $\begin{array}{l}\text { Possible risk of overweight ( } \\
>+1 S D-\leq+2 S D \text { ) }\end{array}$ & 0 & 0 \\
\hline & Overweight $(>+2 S D-\leq+3 S D)$ & 0 & 0 \\
\hline \multirow[t]{2}{*}{ MUAC } & $\begin{array}{l}\text { Risk of acute malnutrition } \\
(12.5 \mathrm{~cm}-13.5 \mathrm{~cm})\end{array}$ & 37.6 & 20 \\
\hline & $\begin{array}{l}\text { Indicates child is well } \\
\text { nourished }(\geq 13.5 \mathrm{~cm})\end{array}$ & 64.2 & 80 \\
\hline
\end{tabular}




\begin{tabular}{|llll|}
\hline Z-score classification & Interpretation & Baseline & End line \\
& & $\mathbf{n = 2 5 0}$ & $\mathbf{n = 2 5 0}$ \\
& $\mathrm{n}(\%)$ & $\mathrm{n}(\%)$ \\
\hline HAZ = height-for-age & WAZ = weight-for-age & $\begin{array}{l}\text { WHZ = weight- } \\
\text { for-height }\end{array}$ & $\begin{array}{l}\text { WHO = World Health } \\
\text { Organization }\end{array}$ \\
$\begin{array}{l}\text { MUAC = mid-upper arm } \\
\text { circumference }\end{array}$ & & & $\begin{array}{l}\text { SD = standard } \\
\text { deviation }\end{array}$ \\
\hline
\end{tabular}

\section{Discussion}

The findings of this study reveal that an IF diet has an effect on the nutritional status of under-five children attending ECD centres in rural Limpopo. Improvements were observed in all nutrition indicators. According to a UNICEF report, nutrition is central to children's growth and development and is key in meeting the SDG's (21). The majority of children from the current study were growing as expected in accordance with the WHO standard growth chart for children in all indicators (4). The majority were found to have adequate nutritional status and very few were at risk of acute malnutrition and overweight. According to the FBDG, children should be given food that supports their growth indicators for improved nutritional outcomes (22). The statistical difference in the WAZ and MUAC implies that the intervention was effective.

The results of this study suggest that the IF diet provided to the children who participated has a positive effect on the growth and nutritional outcomes of children. A similar observation was reported in the study by Masuda et al., where there was significant change in the growth of children in the experimental group compared to the control group in all growth indicators (5). In the current study, the majority of children had normal growth at baseline, but increases on both WAZ and MUAC were recorded post-intervention. Similar findings were reported in a study conducted in rural Limpopo by Mushaphi et al., where an educational nutrition programme intervention was introduced to under-five children and its effectiveness was demonstrated by an improved nutritional status (12). The current study indicates that there was a significant change on all nutritional indicators. Contrary to this finding, Mushaphi et al. found no changes in growth indicators; stunting, underweight and wasting did not change in either group after their intervention was implemented for one year (12). Our study showed that there was no statistical difference in the HAZ pre- and post-intervention. However, a study conducted in Ethiopia on the effectiveness of spirulina on child malnutrition reported that where the household dietary diversity score increases by one food group, the child's HAZ increases (5). It also indicated a decrease in the mean HAZ as child age increases by one month (5).

The strength of our study is that the majority of the participating children had already been introduced to solid foods, and it was therefore easy for them to consume different types of IF. The study implemented a menu with IF to ensure that all participating ECD centres in the study consumed the same IF. A limitation of this study was the loss of follow up. Some of the children who participated in the pre-intervention 
relocated and changed schools before the end of the intervention. Moreover, school holidays between baseline and endline may have affected the results, as some children were fed foods other than IF despite the agreement to continue with the diet at home.

Based on the above results, we would like to recommend the introduction of an IF diet in all ECD centres in rural areas and primary schools in resource-limited settings to improve children's outcomes. As part of strengthening available interventions, a collaboration between ECDs and the Department of Agriculture to implement centre-based food gardens may ensure the availability and accessibility of IF. That future studies should investigate other interventions that can effectively scale up the use of IF to combat nutrition deficiencies is also recommended.

\section{Conclusion}

The IF diet had an effect on the health outcomes of under-five children's nutritional status and changes were observed after intervention. Our findings suggest that consistency in implementing an IF diet and promoting frequent use of IF can improve nutritional outcomes of children. The ECD centres have a crucial role in shaping children's dietary behaviour and promoting the use of IF diets. Implementation of IF diets in these centres should therefore be used as drivers to promote and scale up the use of IF for improved nutritional outcomes of under-five children in rural areas.

\section{Declarations}

\section{Ethical approval and consent to participate}

A full ethical approval from the Biomedical Research Ethics Committee (BREC) BFC/543/18 was granted by the University of KwaZulu-Natal. Approval from ECD centres, the Department of Social Development (DSD), LPREC/04/2019, and the Department of Health (DoH) in Limpopo Province, 201903-008, was granted. Parents and caregivers of children gave consent for their children to participate in the study.

\section{Consent for publication}

Not applicable

\section{Competing interest}

The authors declare that there is no competing interest in this section.

\section{Funding}

Funding was obtained from University of Kwa-Zulu Natal college of health scholarship which covered only data collection.

\section{Author contributions}


G.N and T.P.M-P conceptualized the study. G.N and B.T carried out the first analysis of the study. G.N produced the first draft of the manuscript. T.P.M-T reviewed the draft and contributed to the final version. All authors have read and agreed to the version of the manuscript.

\section{Acknowledgement}

The author would like to acknowledge the participants who were children attending ECD centres for participating in the study and their parents for giving their consent. Gundo Nepfumbada is supported by the University of KwaZulu-Natal, College of Health Sciences. The funder had no role in the study design, data collection and analysis, decision to publish, or preparation of the manuscript.

\section{References}

1. Dhandevi PEM, Jeewon Rajesh Fruit and vegetable intake: Benefits and progress of nutrition education interventions: narrative review article. 2015;44(10):1309.

2. Gido EO, Ayuya OI, Owuor G, Bokelmann WJA, Economics F. Consumption intensity of leafy African indigenous vegetables: towards enhancing nutritional security in rural and urban dwellers in Kenya. 2017;5(1):14.

3. Bultosa G, Molapisi M, Tselaesele N, Kobue-Lekalake R, Haki GD, Makhabu S, et al. Plant-based traditional foods and beverages of Ramotswa Village, Botswana. 2020;7(1):1.

4. Schembri L, Curran J, Collins L, Pelinovskaia M, Bell H, Richardson C, et al. The effect of nutrition education on nutrition-related health outcomes of Aboriginal and Torres Strait Islander people: a systematic review. 2016;40(S1):S42-S7.

5. Masuda K, Inoue Y, Inoue R, Nakamura A, Chitundu M, Murakami J, et al. Spirulina effectiveness study on child malnutrition in Zambia. 2014.

6. De Jager I, Giller KE, Brouwer ID, Food and nutrient gaps in rural Northern Ghana: Does production of smallholder farming households support adoption of food-based dietary guidelines? 2018;13(9).

7. Fanzo J. Strengthening the engagement of food and health systems to improve nutrition security: Synthesis and overview of approaches to address malnutrition. Global Food Security. 2014;3(34):183-92.

8. Fanzo J, Hawkes C, Udomkesmalee E, Afshin A, Allemandi L, Assery O, et al. 2018 Global Nutrition Report. 2019.

9. Bourne L. Stakeholder relationship management: a maturity model for organisational implementation: CRC Press; 2016.

10. Vorster HH, Badham J, Venter CS: An introduction to the revised food-based dietary guidelines for South Africa. 2013;26(3):S5-S12.

11. Ghosh-Jerath S, Downs S, Singh A, Paramanik S, Goldberg G, Fanzo JJBph. Innovative matrix for applying a food systems approach for developing interventions to address nutrient deficiencies in indigenous communities in India: a study protocol. 2019;19(1):944. 
12. Mushaphi LF, Dannhauser A, Walsh CM, Mbhenyane XG, Van Rooyen FC. Effect of a nutrition education programme on nutritional status of children aged 3 - 5 years in Limpopo Province, South Africa. South African Journal of Child Health. 2015;9(3).

13. Gottfried AE, Nylund-Gibson K, Gottfried AW, Morovati D, Gonzalez AM. Trajectories from academic intrinsic motivation to need for cognition and educational attainment. Journal of Educational Research. 2017;110(6):642-52.

14. White JM, Bégin F, Kumapley R, Murray C, Krasevec JJM. Complementary feeding practices: Current global and regional estimates. 2017;13:e12505.

15. Verstraeten R, Van Royen K, Ochoa-Avilés A, Penafiel D, Holdsworth M, Donoso S, et al. A conceptual framework for healthy eating behavior in Ecuadorian adolescents: a qualitative study. 2014;9(1).

16. Okoye J, Oni KJJoFS. Promotion of indigenous food preservation and processing knowledge and the challenge of food security in Africa. 2017;5(3):75-87.

17. Drammeh W, Hamid NA, Rohana AJCRiN, Journal FS. Determinants of Household Food Insecurity and Its Association with Child Malnutrition in Sub-Saharan Africa: A Review of the Literature. 2019;7(3):610-23.

18. Desa U. Transforming our world: The 2030 agenda for sustainable development. 2016.

19. Mbhatsani VH, Mbhenyane XG, Mabapa SNJEof, nutrition. Development and Implementation of Nutrition Education on Dietary Diversification for Primary School Children. 2017;56(6):449-61.

20. Organization WH. United Nations Children's Fund. WHO child growth standards and the identification of severe acute malnutrition in infants and children. Geneva and New York: WHO and Unicef, 2009. 2015.

21. Unicef. Multi-sectoral approaches to nutrition: nutrition-specific and nutrition-sensitive interventions to accelerate progress. 2016.

22. Vorster HE. The new South African food-based dietary guidelines in perspective. The Nutrition Society of South Africa. 2015.

23. Almalki SJJoe, learning. Integrating Quantitative and Qualitative Data in Mixed Methods Research: Challenges and Benefits. 2016;5(3):288-96.

24. Schoonenboom J, Johnson RBJKKZfSuS. How to construct a mixed methods research design. 2017;69(2):107-31.

25. Erlingsson C, Brysiewicz PJAJoEM. A hands-on guide to doing content analysis. 2017;7(3):93-9.

26. Chamane N, Kuupiel D, Mashamba-Thompson TPJD. Stakeholders' Perspectives for the Development of a Point-of-Care Diagnostics Curriculum in Rural Primary Clinics in South Africa-Nominal Group Technique. 2020;10(4):195. (26) http://www.statssa.gov.za/?page_id=993\&id=fetakgomomunicipality

27. Municipality FTL. 2019/20 FINAL IDP/BUDGET. 2019.

28. Öhlmann P, Hüttel SJDSA. Religiosity and household income in Sekhukhune. 2018;35(2):179-93. 
29. Mpandeli S, Nesamvuni E, Maponya PJJoAS. Adapting to the impacts of drought by smallholder farmers in Sekhukhune District in Limpopo Province, South Africa. 2015;7(2):115.

30. Organization WH. United Nations Children's Fund. WHO child growth standards and the identification of severe acute malnutrition in infants and children. Geneva and New York: WHO and Unicef, 2009. 2015.

31. Alemu ZA, Ahmed AA, Yalew AW, Birhanu BS, Zaitchik BF. Individual and community level factors with a significant role in determining child height-for-age $Z$ score in East Gojjam Zone, Amhara Regional State, Ethiopia: a multilevel analysis. Archives of Public Health. 2017;75(1):27. 